\title{
REVIEW I Music as Multimodal Discourse: Semiotics, Power and Protest
}

\author{
Lyndon C. S. Way and Simon McKerrell Eds.
}

London: Bloomsbury, 2017

ISBN: $9781474264425(\mathrm{HB})$

\section{John Mullen}

\section{Université de Rouen}

john.mullen@wanadoo.fr

From its beginnings in the 1970s, popular music studies have underlined the parallel activities and channels involved in the production and consumption of a song. Melody, drumming, vocal staging, voice quality, performance, clothing, and many other aspects simultaneously produce their effect. Such simultaneity is implicit in discussions such as Hennion and Vignolle (1978), and explicit in such contributions as Tagg (1987). The present book appears to be addressed to people working in discourse analysis and is a plea for music to be taken seriously by the discipline, whose scholars, we are told, are more accustomed to analysing news bulletins and political speeches: "[w]e believe that music and sound are not trivial concerns for scholars of communication and media" (8). The ten chapters, of which chapter one is a theoretical introduction, present nine case studies of analysis in musical communication.

The work is published in the Bloomsbury collection Advances in Semiotics, a refreshing series including a book on the semiotics of clowns and clowning, another on drink and drinking, and a third on the semiotics of emoji, as well as works on more traditional subjects such as the semiotics of happiness, and that of religion. The contributors to the present volume come from linguistics, musicology, media studies, and sociology. Five of the chapters examine different ways popular music and radical protest can intertwine, whereas one chapter looks at far-right uses of music, and another with the putting down of subaltern voices through music. Two deal with very specific genres of musical production: the sonic logo (think the sound Windows makes by default on start-up); and the advertising jingle. This mixture justifies the subtitle of the book: semiotics, power, and protest.

In the first study, Eriksson and Machin make a convincing presentation of how music in a reality TV show about a campsite engages in the ridiculing of workingclass people who appear in the show. The editing of the footage, through selection 
and also through the music added, encourages a middle-class gaze of mockery. To deepen the analysis, the authors tease out the meaning potentials of different aspects of pitch and rhythm.

Dillane, Power and Devereux analyse the social and political meaning of a single 2004 song by Morrissey, "The Slum Mums". If the lyrics were read by a naïve listener, they could easily conclude that the song expressed scorn and disgust for young working-class mothers, in accord with the moral panic which some neoliberal politicians have fostered concerning a supposed dependency culture. The message of the song is quite different from that, though. Morrissey's use of voice, and the audience's knowledge of the rest of his repertoire and of the political context of the UK in 2004, allow the irony to be understood. The song, say the researchers, aims at encouraging the audience to be temporarily tempted by feelings of hostile disgust towards the "slum mums". Voice, lyrics, and the effects of Morrissey's (sub)cultural capital as a raconteur of the marginalized are the tools which work multimodally to give a final, complex result. The work, they insist, "has the potential to force audiences to deal with their own prejudices" (63).

Richardson deals with the ways that fascist organizations have used music. He looks at Rock against Communism, launched in the 1980s in the UK by far-right organizations, despite the distaste, on the part of much of their leadership, for "discordant music". In the concerts, the songs were mostly written by the bands involved, but fascists have other ways of using music. Richardson looks at the fourteen songs in the National Front Songbook (which include "Scarborough Fair"), and finally examines the fascinating example of "Tomorrow Belongs to Me", written by an antifascist songwriter for the musical show Cabaret. A rocked-up cover version of the piece was recorded by a fascist group.

Way, one of the editors, contributes a chapter on a popular Turkish band and how they used a choreography of modern dance representing well-known scenes from battles with police during the Gysi protests of 2013. The YouTube version of the video became very popular indeed. One's image of the radicality of the group might be affected by the fact that they agreed to make an alternate version to comply with television censorship, a version which made no reference to the protests. Nevertheless, the author asks us to be generous with the band, since channels to express protest to a broad audience are rare in today's Turkey. In a close analysis of the video, the ways in which types of authenticity are coded into the performance (music, lyrics, clothes, gesture, and so on) are well-explained, and a strong typology of authenticities is presented. However, this analysis should have been pushed further, since the basis of the choreography is not the protests themselves, but rather the media reports of the protests, which highlight individual anecdotes, in particular those involving good-looking women, rather than collective efforts. It is significant that the video itself is built around gorgeous young men and women dancers, echoing media tropes of the representation of mass protest.

The following chapter, by Van Leeuwen, takes us away from the world of popular song, in a useful reminder of the ubiquity of music in our lives. Van Leeuwen deals with the importance of the sonic logo (and as I write, the French railways are playing me a heraldic dididum dum da da in apt illustration of this). He begins by summarizing some of the often ignored presences of sound design in our everyday lives ("car manufacturers know that car doors should sound reassuringly solid when they are closed" -124) and analyses how meaning potential is used in sonic logos. "Since we know that a rough voice can come from a tough day or a hard life, and from illness and distress, this gives roughness a meaning potential which can be used" (123). The author gives an overview of some of the key findings in research on sonic logos. 
Wingstedt tackles the advertising jingle and the interaction between its multimodal components: voice, music, and lyrics. Rather surprisingly, he chooses very old advertisements (from the 1950s and the 1970s), but the close reading of instrumentation and melody in semiotic terms is illuminating. He concludes by quoting Cook: "instead of talking about meaning as something that the music has, we should be talking about it as something that the music does (...) within a given context" (Cook 1998: 146).

For chapter eight we return to political themes, and Filardo-Llamas proceeds with a semiotic analysis of two Spanish popular songs (and their music videos) dealing with the issue of domestic violence. One is a hit from 2004, the other a more recent rap song. Music, camera angle, lyrics, and other elements are moulded together for the final effect, and the author feels that such messages in a popular mode might well be more effective than series of official posters, for example. The account would have been usefully supplemented by a consideration of the narrator role taken on by the listener joining in with the sing-along chorus. Multimodality is not just a matter of multiple channels going from producer/artiste to consumer, but also different positionings taken on by the consumer who participates by (for example) singing along, dancing, commenting, or judging.

In the penultimate chapter, Barrett looks at indigenous hip-hop in Guatemala. Some popular Mayan music has entered the commercial mainstream in Guatemala, usually in instrumental forms. Mayan activists consider that this has been a form of cultural appropriation which silences the voices of the indigenous peoples. This has led to initiatives to produce hip-hop centred on indigenous languages and traditions. Lyrics are sometimes written by artistes in a meditative trance, and concerts begin with pre-Columbian Mayan prayers. One of the objectives of the artistes is to contradict the colonial image of indigenous cultures as primitive or dying.

The final chapter, by Ord, examines British folk rock music and counter-cultural content. More specifically, it looks at the development of sound recording techniques and their role in British folk rock, in tension between artistic ambition and duties to authenticity. Widening the stereo field is used to indicate a broadening of spiritual horizons of the narrator in some of Pentangle's songs, for example, and other similar techniques of echoing thematic content in studio post-production are explained

This volume offers a useful collection of studies. The more theoretical first chapter traces the history of the multimodal approach, and explains the position of the editor with relation to more established analyses such as that of Philip Tagg. It goes on to examine key concepts in popular music culture, such as that of authenticity, noting that "musical authenticity (...) is today properly conceived of as a social process of continual renegotiation of the shared truth and canonical values of a particular musical community" (p.6). As I suggested at the beginning of this review, pointing out that simultaneous communication through music has been discussed for several decades, not everyone in popular music studies will find the claims to theoretical innovation convincing. There is not really a strong thread linking the chapters together, and two or three of them are mainly descriptive. Nevertheless, the majority of the individual case studies are skilfully drawn and very thought-provoking.

\section{References}

Cook, N. 1998. Analysing Musical Multimedia. Oxford: Oxford University Press. 
Hennion, A., and Vignolle, J. P. 1978. Artisans et industriels du disque - essai sur le mode de production de la musique. Paris: CSI-Cordes.

Tagg, P. 1987. "Musicology and the Semiotics of Popular Music." Semiotica 66 (1/3): 279- 298. 